which case the label $R$ should be used rather than $K$. From the statements of Theorem $(8,1)$, page 19 , and line 3 of page $20, K$ subtends an angle less than $\phi$ at $\zeta$. Consequently, the angle marked $\phi$ in Fig. $(8,1)$ seems inconsistent, as does the phrase "where, however, $K$ subtends at $\zeta$ the angle $\phi$ " of line 2, page 20 . On page 48, last line, the subscripts on $z_{1}, z_{2}$ should be removed.

In closing, it is perhaps not out of place to observe that many valuable contributions to the theory expounded in this book are due to J. L. Walsh and the author.

I. M. SHeFfer

\title{
NEW PUBLICATIONS
}

Delachet, A. L'analyse mathêmatique. Paris, Presses Universitaires de France, 1949. $118 \mathrm{pp}$.

Electromagnetic theory. (Proceedings of Symposia in Applied Mathematics, vol. 2.) New York, American Mathematical Society, $1950.4+91$ pp. $\$ 3.00$.

Hossner, A. Einfihhrung in die höhere Mathematik. Vienna, Springer, 1949. 10+359 pp. $\$ 6.00$.

LANGER, R. E. Fourier's series, the genesis and evolution of a theory. (Herbert Ellsworth Slaught Memorial Papers, no. 1.) Buffalo, Mathematical Association of America, 1949. $5+86$ pp. $\$ 1.00$.

DE LA Vallee Poussin, C. J. Le potentiel logarithmique. Belayage et représentation conforme. Louvain, Librarie Universitaire, 1949. $12+452$ pp.

MAGnus, W. See OberhetTinger, F.

Non-linear problems in mechanics of continua. (Proceedings of Symposia in Applied Mathematics, vol. 1.) New York, American Mathematical Society, 1949. 8+219 pp. $\$ 5.25$.

Oberhettinger, F., and Magnus, W. Anwendung der elliptischen Funktionen in Physik und Technik. (Die grundlehren der Mathematischen Wissenschaften, vol. 55.) Berlin, Springer, 1949. 7+126 pp. 15.60 DM.

Pelletier, J. L. L'age des mathematiques. Paris, L'office de Documentation Bibliographique, 1949. $\$ 3.00$.

Tables of the Bessel functions of the first kind of orders fifty-two through sixty-three. (The Annals of the Computation Laboratory of Harvard University, vol. 11.) Cambridge, Harvard University Press, 1949. $12+544$ pp. $\$ 8.00$. 